Brit. J. industr. Med., 1952, 9, 303.

\title{
STUDIES ON COTTON DUST IN RELATION TO BYSSINOSIS \\ PART III : COMPARISON OF COTTON DUST AND HOUSE DUST BY CHEMICAL AND SKIN TESTS \\ BY
}

\author{
H. R. CAYTON, G. FURNESS*, D. S. JACKSON $\dagger$, and H. B. MAITLAND \\ From the Department of Bacteriology, University of Manchester
}

(RECEIVED FOR PUBLICATION JULY 3, 1952)

In an earlier paper Cayton, Furness, and Maitland (1952) showed that extracts of cotton dust produced two types of skin reaction, an early reaction of wheal and flare and a late reaction of induration and erythema. These two reactions appeared to be caused by different substances. The late reaction was possibly a direct effect of some toxic component. The early reaction was of the type associated with allergy of the asthma-urticaria type, but it did not denote specific hypersensitivity peculiar to byssinosis because other groups of the adult urban population reacted equally with byssinotics although they had never been exposed to cotton dust and did not suffer from any allergic symptoms. The early reaction may, however, have indicated hypersensitivity to an allergen that was widely distributed.

In continuing this work preliminary chemical testing of cotton dust extracts suggested the possibility that they might contain similar components to those reported for house dust extracts by Rimington, Stillwell, and Maunsell (1947). House dust extracts also elicited the early type of skin reaction (Maunsell, Whetnall, and Rimington 1947). The further comparison of a cotton dust extract with house dust extracts is the subject of this paper.

\section{Chemical Tests}

Examination of Cotton Dust Extract.-Three extracts obtained by different methods from one sample of cotton dust were examined qualitatively by a number of chemical tests (Table 1). The details of preparing the extracts (designated I, II, and III) and the source of the dust will be found in an earlier paper (Cayton and others, 1952). The methods of extraction were respectively, that of Prausnitz (1936), a modification of this,

\footnotetext{
* In receipt of a grant from the British Cotton Industry Research Association.

† Research assistant in biochemistry, Rheumatism Research Centre.
}

TABLE 1

RESULTS OF CHEMICAL TESTS APPLIED TO EXTRACTS

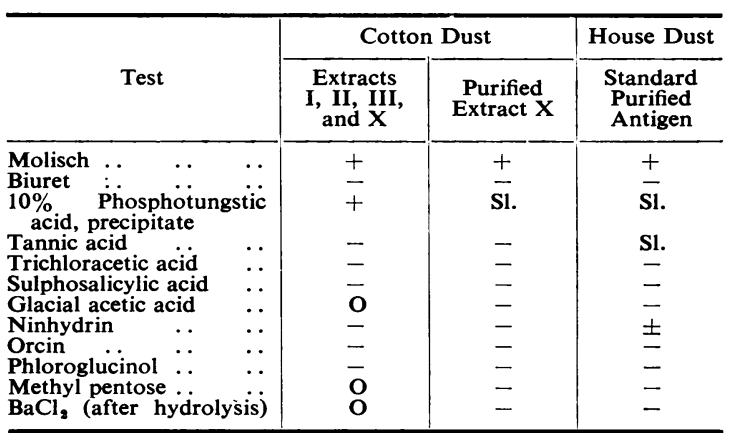

$$
\mathrm{O}=\text { not tested. } \text { SI. = slight. } \pm=\text { faint positive. }
$$

and the method of Cooke (1947). These extracts behaved alike. Only the Molisch test and precipitation with phosphotungstic acid were positive. The biuret test was negative even when applied to extract II after it had been concentrated about seventeenfold. The results would be consistent with the presence of a carbohydrate possibly associated with a protein moiety.

The corresponding extracts of house dust, the "standard crude antigen" of Rimington and others (1947), had given a positive Molisch reaction and a negative or doubtful biuret reaction, so that the two kinds of dust, extracted by different methods, had yielded extracts that were, in these respects, similar.

Extract X, the details of which were stated by Cayton and others (1952), was examined more fully. It was made by a modification of Cooke's (1947) method. After the dust had been de-fatted it was extracted with Coca's (1922) buffered saline solution, partially clarified in the centrifuge, and dialysed against Evans' (1922) saline for four days, changing the saline daily. The extract was then finally clarified in the centrifuge and sterilized by filtration through a gradacol membrane.

Nitrogen was determined by the micro-Kjeldahl 
method. Combined hexose was determined by the orcinol method (Rimington, 1940) using galactose as the standard. Reducing sugars were determined by the method of Somogyi (1945). Ashing was carried out at $500^{\circ} \mathrm{C}$. in platinum crucibles and the ash weighed as sulphate.

This extract, which was soluble in water, conformed with extracts I, II, and III (Table 1) in giving a strong Molisch reaction, and negative biuret and ninhydrin reactions. It afforded the following analytical figures which are shown alongside those for "standard crude antigen" reported by Rimington and others (1947).

\begin{tabular}{|c|c|c|c|}
\hline & & Extract $\mathrm{X}$ & $\begin{array}{c}\text { Standard Crude } \\
\text { Antigen }\end{array}$ \\
\hline $\begin{array}{l}\text { Hexose (as galactose). } \\
\text { Nitrogen } \ldots \\
\text { Ash (as sulphate) }\end{array}$ & 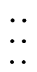 & $\begin{array}{r}20 \cdot 5 \% \\
2 \cdot 5 \% \\
45 \cdot 0 \%\end{array}$ & $\begin{array}{l}20-30 \% \\
2-3 \% \\
35-50 \%\end{array}$ \\
\hline
\end{tabular}

Examination of Purified Extract.-Another sample of extract $X$, prepared as described above, except that in this instance it was dialysed against running water instead of Evans' saline, was purified by the same method as Rimington used for the standard crude antigen. The finished extract was dialysed further against $2 \%(\mathrm{w} / \mathrm{v})$ citric acid for 48 hours. This was followed by acetone precipitation. Acetone to $25 \%$ concentration was added and the solution stood overnight at $4^{\circ} \mathrm{C}$.; no precipitate was obtained. The acetone concentration was increased and a small amount of precipitate was obtained at $50 \%$ concentration. This was discarded and the precipitate obtained at $75 \%$ concentration was centrifuged, washed with acetone, and dried in vacuo. This was the purified extract. No further precipitate was obtained at an acetone concentration up to $90 \%$.

The material was yellowish brown and sparingly soluble in water. The results of colour and precipitation tests agreed in the main with those reported for " standard purified antigen", the difference being that the house dust extract gave a faintly positive ninhydrin test for free amino-groups and a slight precipitate with tannic acid (Table 1). The analytical figures obtained for the purified extract are shown alongside those for "standard purified antigen".

\begin{tabular}{|c|c|c|}
\hline & $\begin{array}{l}\text { Purified } \\
\text { Extract X }\end{array}$ & $\begin{array}{l}\text { Standard } \\
\text { Purified } \\
\text { Antigen }\end{array}$ \\
\hline $\begin{array}{l}\text { Hexose (as galactose).. } \\
\text { Nitrogen } \ldots \\
\text { Reducing power (as galactose) } \\
\text { Ash (as sulphate) }\end{array}$ & $\begin{array}{r}49 \cdot 2 \% \\
5 \cdot 2 \% \\
1 \cdot 2 \% \\
1 \cdot 0 \%\end{array}$ & $\begin{array}{l}40-60 \% \\
5-7 \% \\
1.5 \% \\
1-2 \%\end{array}$ \\
\hline
\end{tabular}

Chromatographic Examination.-Purified extract . X, in $10 \mathrm{mg}$. portions, was hydrolysed at $100^{\circ} \mathrm{C}$. for 24 hours in $6 \mathrm{~N} \mathrm{HC1}$, in sealed tubes, and the hydrolysate examined by the technique of partition chromatography (Consden, Gordon, and Martin, 1944). Phenol and butanol-acetic acid-water $(40: 10: 50)$ were used as solvents. The amino-acids detected were cysteic acid (from cystine), glutamic acid, aspartic acid, serine, glycine, threonine, alanine, proline, valine, and leucine.

With the exception of cysteic acid these were the amino-acids that Rimington and his colleagues found in their "standard purified antigen" which contained in addition a little arginine and a trace of glucosamine. They were also the amino-acids present in the hydrolysate of materials, predominantly polysaccharide in character, isolated from moulds (Stillwell, Rimington, and Maunsell, 1947) except that proline was not found in the moulds.

To identify sugars, $10 \mathrm{mg}$. portions of purified extract $\mathrm{X}$ were hydrolysed for four hours at $100^{\circ} \mathrm{C}$. with $0.5 \mathrm{~N}$ $\mathrm{H}_{2} \mathrm{SO}_{4}$ in sealed tubes (Flood, Hirst, and Jones, 1947) and the hydrolysate examined by the procedure of Partridge (1948) using both phenol and butanol-acetic acid-water $(40: 10: 50)$ as solvents. The papers were sprayed with the aniline-phthalate reagent of Partridge (1949), the naphtho-resorcinol reagent of Forsythe (1948), and the Elson and Morgan reagent for hexosamines of Partridge (1948). The main sugars identified were galactose, glucose, and arabinose. L-fucose was also present and traces of two sugars with RF values corresponding to ribose and rhamnose were detected. An unknown reducing substance, moving slowly in both solvents, was also found (Table 2). A yellow pigment remained stationary at the starting point in both solvents.

TABLE 2

${ }^{R} F$ VALUES OF PURE SUGARS AND REDUCING SUBSTANCES PRESENT IN ACID HYDROLYSATE OF PURIFIED EXTRACT $X$

\begin{tabular}{|c|c|c|c|c|c|}
\hline & & \multicolumn{2}{|c|}{ Pure Sugars } & \multicolumn{2}{|c|}{ Hydrolysate } \\
\hline & & Phenol & $\begin{array}{c}\text { Butanol- } \\
\text { Acetic } \\
\text { Acid }\end{array}$ & Phenol & $\begin{array}{l}\text { Butanol- } \\
\text { Acetic } \\
\text { Acid }\end{array}$ \\
\hline $\begin{array}{l}\text { Glucose } . . \\
\text { Galactose .. } \\
\text { Arabinose.. } \\
\text { Mannose .. } \\
\text { L-fucose . } \\
\text { Ribose* } . \\
\text { Rhamnose* } \\
\text { Unknown }\end{array}$ & $\begin{array}{l}\cdots \\
\cdots \\
\cdots \\
\cdots \\
\cdots \\
\cdots\end{array}$ & $\begin{array}{l}0.39 \\
0.43 \\
0.51 \\
0.45 \\
0.63 \\
0.59 \\
0.59 \\
-\quad\end{array}$ & $\begin{array}{l}0 \cdot 18 \\
0 \cdot 17 \\
0 \cdot 25 \\
0 \cdot 20 \\
0 \cdot 27 \\
0 \cdot 31 \\
0.37 \\
-\end{array}$ & $\begin{array}{l}0.39 \\
0.43 \\
0.52 \\
\overline{0.61} \\
- \\
\overline{0.08}\end{array}$ & $\begin{array}{l}0 \cdot 18 \\
0 \cdot 17 \\
0 \cdot 25 \\
\overline{0.27} \\
0.32 \\
0 \cdot 38 \\
0.07\end{array}$ \\
\hline
\end{tabular}

* Figures extracted from Partridge (1948)

The report of Rimington and others (1947) that a similar analysis of "standard purified antigen" yielded only galactose has been amplified by more recent analysis (Rimington and Cummings, personal communication). Using finer methods, arabinose and xylose have also been found, together with small quantities of rhamnose and possibly traces of galacturonic acid and an unknown sugar, although some of the sugars present in small quantities might be impurities. The aminoacids were substantially as reported before and in the following percentages :-aspartic acid 6, glutamic acid $15 \cdot 5$, glycine 22 , serine 16 , valine 5 , leucine 7 , arginine or lysine 5 , proline \pm .

Thus the purified extract of cotton dust was similar, in its general properties, to the "standard purified antigen" obtained from house dust and to material extracted from moulds. All contained a polysaccharide associated with a polypeptide grouping of amino-acids giving none of the usual colour reactions for protein. 


\section{Skin Tests}

In view of the chemical similarity of the cotton dust and house dust extracts, the skin reactions produced by them in the same persons were compared.

The technique adopted for the intradermal test was described in an earlier paper (Cayton and others, 1952) and was used throughout unless otherwise stated. The amount injected was $0.02-0.03 \mathrm{ml}$. and saline was always injected as a control. The dilutions referred to were made from a $1 / 1000 \mathrm{w} / \mathrm{v}$ solution unless otherwise stated.

Heat Stability of Cotton Dust Extracts.-The cotton dust extracts used for skin testing as reported in the paper mentioned above had been sterilized by filtration, with the exception of extract IV, which was prepared after the method of Rimington and others for house dust and immersed in boiling water for 30 minutes on each of three successive days. It appeared to be as active as filtered extracts in causing skin reactions. To confirm this, and to test the heat stability of the active substance at a temperature which would kill bacterial spores present in cotton dust (Furness and Maitland, 1952), samples of a $1 / 100$ dilution of extract $X$, unheated and autoclaved at $10 \mathrm{lb}$. for 20 minutes, were compared by injecting them intradermally into each of a number of normal persons. These samples were alike as regards the incidence of early reactions they produced, and the size of reactions was also similar, as shown below. The heat stability of cotton dust extract was therefore another point of resemblance with house dust extracts.

\begin{tabular}{|c|c|c|c|c|c|c|}
\hline \multicolumn{2}{|c|}{$\begin{array}{l}\text { Unheated } \\
\text { Extract }\end{array}$} & \multicolumn{2}{|c|}{$\begin{array}{c}\text { Autoclaved } \\
\text { Extract }\end{array}$} & \multicolumn{3}{|c|}{$\begin{array}{l}\text { Saline } \\
\text { Control }\end{array}$} \\
\hline $\begin{array}{r}6 \\
7 \\
6 \\
10 \\
9 \\
5\end{array}$ & $\begin{array}{c}32 \dagger \\
7 \\
19 \\
35 \\
35 \\
23\end{array}$ & $\begin{array}{l}7 \\
7 \\
5 \\
8 \\
8 \\
4\end{array}$ & $\begin{array}{r}28 \\
7 \\
5 \\
35 \\
35 \\
15\end{array}$ & 3 & $\begin{array}{l}\text { 二 } \\
z\end{array}$ & 17 \\
\hline
\end{tabular}

* Diameter of the wheal in $\mathrm{mm}$. † Diameter of the whole reaction, including erythema, in $\mathrm{mm}$.

Activity of Purified Extract X.-The activity of the purified extract $X, 1 / 100$ and $1 / 10$, was compared with the original extract, $1 / 100$, by testing them on 33 normal persons. The purified extract was adjusted so that the hexose content of the two extracts was similar on the assumption that the biologically active substances might be associated with the carbohydrate complex. The purified extract contained therefore about $2 / 5$ as much total solid as the original extract.

The $1 / 100$ dilution of purified extract caused fewer and smaller reactions of the early type than the same dilution of the original extract, but the $1 / 10$ dilution of purified extract was practically identical with the $1 / 100$ dilution of the original. Some typical examples of the comparative tests are shown below.

Although the purified extract was somewhat weaker than the original extract in causing the early type of reaction, it was still very effective.

As judged also by the late reaction, the purified extract was somewhat weaker than the original. Com-

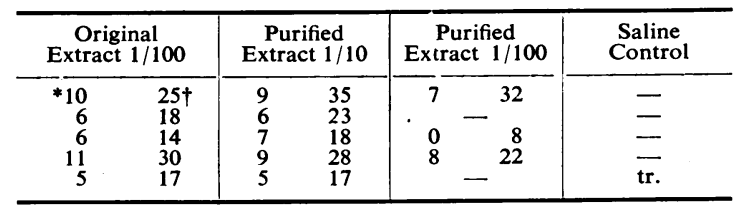

* Diameter of wheal in $\mathrm{mm}$. † Diameter of whole reaction, including erythema, in $\mathrm{mm}$.

paring a $1 / 100$ dilution of each, the purified extract produced fewer and smaller reactions. The $1 / 10$ dilution of the purified extract was again about equal in activity to the $1 / 100$ dilution of the original. It is, however, of interest that the substances causing both the early and late reactions were not lost during purification.

Comparison of Extracts of Cotton and House Dust by Skin Tests on the Same Persons.-Extract X (not purified) was tested by intradermal injection in comparison with a corresponding extract of house dust, the "standard crude antigen", also known by the trade name "domogen " which is a $1 / 1000(\mathrm{w} / \mathrm{v})$ solution of dried extract. This solution will be referred to as S.C.A. Extract $X$ was calculated to be approximately the same strength. Dilutions mentioned subsequently were made from these solutions.

Both early and late skin reactions were recorded. The early reaction, read about 10 minutes after injection, was positive if there was a wheal (usually over $5 \mathrm{~mm}$. across) and erythema with an overall diameter of 10 $\mathrm{mm}$. or more. The late reaction was read about six to nine hours after injection and was positive if $5 \mathrm{~mm}$. or more across. A control was considered to be positive if there was, for the early reaction, a wheal and flare of $10 \mathrm{~mm}$. and, for the late reaction, a red thickened area of $4 \mathrm{~mm}$. The appearances and the reading of these reactions were fully described in an earlier paper (Cayton and others, 1952).

Forty-three adults, including departmental staff, students, and some hospital patients, were tested. None had been exposed to cotton dust or was suffering from any allergic complaint. Two cases were excluded on account of their control reactions.

Early Reactions.-In analysing the results of the early reactions it will be noted (Table 3 ) that in the first seven cases extract $X 1 / 10$ was compared with S.C.A. 1/100. Five cases behaved alike to both extracts; two were positive, one reacted weakly (negative), and two had no reaction. Of the other two cases one was positive to each extract and negative to the other. There was not much difference in the size of the reactions in those who reacted to both.

In 34 cases (nos. 8-41) both extracts were used in a dilution of $1 / 10$. The results were similar in 22 cases (15 positive, six no reaction, and one negative, weak reaction). There was a reaction with extract $X$ only in 12 cases (nine positive and three small reactions classed as negative). When both extracts produced a reaction there was, on the whole, no significant difference in size or appearance. The results of the entire series can be summarized as follows :- 
TABLE 3

COMPARISON OF EARLY AND LATE SKIN REACTIONS PRODUCED BY EXTRACTS OF COTTON DUST (EXTRACT X) AND OF HOUSE DUST (STANDARD CRUDE ANTIGEN) IN THE SAME PERSONS

\begin{tabular}{|c|c|c|c|c|c|c|}
\hline \multirow{3}{*}{$\begin{array}{l}\text { Case } \\
\text { No. }\end{array}$} & & & \multicolumn{4}{|c|}{ Early Reaction } \\
\hline & \multicolumn{2}{|c|}{$\underset{1 / 10}{\text { Extract }} \mathrm{X}$} & \multicolumn{4}{|c|}{$\begin{array}{l}\text { S.C.A. } \\
1 / 100\end{array}$} \\
\hline & $\begin{array}{l}\text { Wheal } \\
(\mathrm{mm} .)\end{array}$ & $\begin{array}{l}\text { Wheal }+ \\
\text { Erythema } \\
\text { (mm.) }\end{array}$ & Result & & $\begin{array}{l}\text { Wheal } \\
\text { mm.) }\end{array}$ & \\
\hline $\begin{array}{l}8 \\
9 \\
10 \\
11 \\
12(1) \\
13(2) \\
14 \\
15 \\
16 \\
17 \\
18 \\
19 \\
20 \\
21 \\
22 \\
23 \\
24 \\
25 \\
26 \\
27 \\
28 \\
29 \\
30 \\
31 \\
32 \\
33(4) \\
34 \\
35 \\
36 \\
37 \\
38 \\
39 \\
40 \\
41\end{array}$ & $\begin{array}{l}5 \\
8 \\
8 \\
9 \\
10 \cdot 5 \\
9 \\
6 \\
7 \\
7 \\
6 \\
6 \\
12 \\
10 \\
7 \\
7 \cdot 5 \\
7 \\
6 \cdot 5 \\
6 \cdot 5 \\
6 \\
8 \\
7 \\
6 \\
8 \\
5 \\
5 \\
5 \\
5 \\
4 \\
-4(\mathrm{p}) \\
(\mathrm{p}) \\
\mathrm{tr} \\
4(\mathrm{p})\end{array}$ & $\begin{array}{c}22 \\
33 \\
-7 \\
- \\
- \\
10 \\
\text { Extract X } \\
1 / 10 \\
25 \\
34 \\
22 \\
41 \\
28 \\
30 \\
21 \\
9 \\
30 \\
15 \\
20 \\
42 \\
44 \\
31 \\
26 \\
8 \cdot 5 \\
22 \\
10 \\
14 \\
26 \\
21 \\
26 \\
41 \\
16 \\
16 \\
8 \\
7 \\
10 \\
- \\
-8 \\
- \\
6 \\
17 \\
\end{array}$ & $\begin{array}{l}+ \\
+ \\
+ \\
+ \\
+ \\
+ \\
+ \\
+ \\
+ \\
+ \\
+ \\
+ \\
+ \\
+ \\
+ \\
+ \\
+ \\
+ \\
+ \\
+ \\
+ \\
+ \\
+ \\
+ \\
+ \\
- \\
- \\
- \\
- \\
- \\
-\end{array}$ & & $\begin{array}{c}7 \cdot 5 \\
4 \cdot 5 \\
5 \cdot 5 \\
3 \cdot 5 \\
- \\
- \\
4 \\
\text {.C.A. } \\
1 / 10 \\
7 \\
7 \\
7 \\
10 \cdot 5 \\
9 \cdot 5 \\
13 \\
5 \\
11 \\
6 \\
10 \\
5 \\
10 \\
16 \\
6 \\
7 \\
5 \\
\frac{\operatorname{tr}(p)}{7} \\
6(\mathrm{p}) \\
(\mathrm{p}) \\
\operatorname{tr} \\
- \\
- \\
\operatorname{tr} \\
\operatorname{tr} \\
- \\
- \\
- \\
4(\mathrm{p}) \\
4(\mathrm{p}) \\
- \\
66(\mathrm{p})\end{array}$ & \\
\hline \multicolumn{7}{|c|}{$\begin{array}{l}\text { (1) Suffered from asthma. } \\
\text { (2) Allergic to cat protein. } \\
\text { (3) Amount injected about } 0.05 \mathrm{ml} \text {. } \\
\text { (4) Said to be sensitive to some drugs. }\end{array}$} \\
\hline \multicolumn{3}{|c|}{ Reactions } & \multicolumn{2}{|c|}{$\begin{array}{l}\text { Case Nos. } \\
\text { in Table } 3\end{array}$} & \multicolumn{2}{|c|}{$\begin{array}{l}\text { Number } \\
\text { of Cases }\end{array}$} \\
\hline \multicolumn{3}{|c|}{$\begin{array}{l}\text { Both extracts positive . } \\
\text { Both extracts negative (no reaction) } . \\
\text { Both extracts negative (weak reactions) } \\
\text { Extract X (only) positive } \\
\text { Extract X (only) weak reaction (negative) } \\
\text { S.C.A. (only) posifive }\end{array}$} & \multicolumn{2}{|c|}{$\begin{array}{l}1,2,8-22 \\
5,6,36-41 \\
4,23 \\
7,24-32 \\
33-35 \\
3\end{array}$} & \multicolumn{2}{|c|}{$\begin{array}{r}17 \\
8 \\
2 \\
10 \\
3 \\
1\end{array}$} \\
\hline
\end{tabular}

The two extracts gave the same result (positive, weak reaction or no reaction) in 27 cases $(66 \%)$. Thirteen cases reacted to extract $\mathrm{X}$ only and one case reacted to S.C.A. only.

It is evident therefore that these two extracts, obtained by different methods from different kinds of dust, were similar; both caused an early type of skin reaction in normal adults, the reactions were indistinguishable, and, further, two-thirds of those tested gave the same result

with each extract. The extracts were, however, not identical, for more people reacted to cotton dust than to house dust and, on the other hand, one person reacted to house dust only.

Late Reactions.-The two extracts differed markedly in producing late reactions, the figures being, for cotton dust extract 32 cases $(80 \%)$ and for house dust extract four cases $(10 \%)$. Three of the four reactions with house dust were small. The result with cotton dust agrees with earlier series of tests (Cayton and others, 1952). The result with house dust agrees with the opinion expressed by Maunsell (personal communication) that late reactions were probably rare, though the point had not been systematically investigated. It is clear however that the late reaction revealed a component in cotton dust extract which was absent or almost absent from the house dust extract. 


\section{Discussion}

The comparisons of cotton dust and house dust extracts reported here have put the study of allergy to cotton dust in a new light. They have shown that it is not an isolated problem but is part of the wider study of allergy to other kinds of dust and in particular to house dust. This general conclusion arises both from the results of chemical examination and from skin testing.

Chemically, a similarity exists between cotton dust and house dust extracts in that both contain a polysaccharide associated with a polypeptide grouping of amino-acids giving none of the usual colour reactions for protein. Although the substances in these extracts have similar general properties they are probably not identical.

The dusts were different in origin and the methods of extraction were also different. The striking fact is that the extracts contained the same type of compound. There is evidence that the cotton dust extract was a mixture, even after its purification, although Rimington and others (1947) considered that the corresponding " standard purified antigen " from house dust contained specific antigenic material in a high state of purity.

Chromatography revealed that the two extracts had nearly the same amino-acids, and that they resembled in this respect material derived from moulds. The component sugars were similar but not identical in the two extracts.

The source of these polysaccharide-polypeptide compounds is not known but it could be moulds and possibly bacteria. The further chemical characterization and differentiation of substances causing the skin reactions, and the detection of their source is obviously desirable.

With regard to skin reactions the two extracts show a similarity and a difference. The difference is revealed by the late type of skin reaction which is produced by cotton dust extracts and not, or only slightly, by a house dust extract. The chemical nature of the substance causing this reaction is not known. It was thought to be an irritant or toxic substance acting directly on the tissues and not concerned in hypersensitivity (Cayton and others, 1952).

The similarity of the extracts is revealed by the early type of skin reaction. The two extracts tested gave almost identical results in $66 \%$ of individuals but the cotton dust extract caused a reaction in more persons than the house dust extract, and the house dust extract caused a reaction in one person negative to cotton dust.

It may be assumed that one or more polysaccharide-polypeptide compounds in the cotton dust extracts were responsible for the early reactions, as Rimington and others (1947) have shown that hydrolysis of these substances in house dust extracts resulted in loss of skin-reacting activity. It is of interest too that both extracts were active after being heated, the house dust at $100^{\circ} \mathrm{C}$. and the cotton dust at about $115^{\circ} \mathrm{C}$.

The comparative skin tests were made on normal adults who had not been exposed to cotton dust and did not suffer from allergic manifestations. It is known from our earlier observations that different groups of adults react similarly to cotton dust and therefore the comparison of the two extracts as here reported would be expected to apply to byssinotics, workers in cotton-mills not exposed to dust, and allergic patients who were sensitive to a variety of allergens.

Reactions to house dust of the early type are considered to indicate allergy, at least in some cases, and there is some supporting evidence for this view (Maunsell and others, 1947). In others, especially those who react only to stronger concentrations, such as we have used here, the significance of the reaction is in doubt. Stillwell and others (1947) wrote " at present we are unable to state whether a threshold reaction to dust antigen at this dilution represents a low grade sensitivity to dust (i.e. a weak reactor) or a non-specific reaction". The dilution referred to was $1 \times 10^{-4} \mathrm{w} / \mathrm{v}$, equivalent to the $1 / 10$ dilution of standard crude antigen used in this work. We have discussed the same problem regarding cotton dust extracts (Cayton and others, 1952) but were uncertain as to whether there was any qualitative difference between those who react to low dilutions and those who are much more reactive. A few persons react to much higher dilutions than others and they may be hypersensitive, but as the reactors to cotton dust may have no clinical manifestations of allergy it is necessary to obtain additional evidence from serology and laboratory tests before being certain how to interpret these reactions. Further work is in progress to determine which, if any, of the reactors (early type of reaction) are hypersensitive. It is clear that such researches on cotton dust have a general significance for the understanding of allergy associated with other kinds of dust and with moulds.

\section{Summary}

An extract of cotton dust has been compared chemically and by skin tests with extracts of house dust. Both contained a polysaccharide associated with a polypeptide grouping of amino-acids giving none of the usual colour reactions for proteins. Quantitative chemical analysis of crude and purified 
extracts from the two kinds of dust showed a marked similarity. Chromatographic examination of the purified extracts, after hydrolysis, revealed a similarity in the sugars and amino-acids detected.

Both extracts produced the early type of skin reaction, and this property resisted heating at about $100^{\circ} \mathrm{C}$.

Cotton dust extract produced a late skin reaction in a high percentage of those tested, whereas the house dust extract did not.

The two extracts were, therefore, not identical. Polysaccharide-polypeptide compounds were probably responsible for the early skin reaction. Their source is not known but they could come from moulds or possibly bacteria.

The significance of these results in relation to byssinosis and to allergy is discussed.

We gratefully acknowledge a grant from the British Cotton Industry Research Association for technical assistance and supplies. We wish to thank the members of the clinical staff of the Manchester Royal Infirmary for providing facilities, and particularly students and others who volunteered for skin testing. The standard crude antigen produced as "domogen" by Messrs. Duncan and Flockhart, Edinburgh, was kindly supplied by Dr. Kate Maunsell.

\section{REFERENCES}

Cayton, H. R., Furness, G., and Maitland, H. B. (1952). British Journal of Industrial Medicine, 9186

Coca, A. F. (1922). J. Immunol., 7, 163.

Consden, R., Gordon, A. H., and Martin, A. J. P. (1944). Biochem. J., 38, 224.

Cooke, R. A. (1947). Allergy in Theory and Practice. Philadelphia.

Evans, A. C. (1922). J. infect. Dis., 30, 95.

Flood, A. E. Hirst, E. L., and Jones, J. K. N. (1947). Nature, Lond., 160, 86.

Forsyth, W. G. C. (1948). Ibid, 161, 239.

Furness, G., and Maitland, H. B. (1952). British Journal of Industrial Medicine 9,138 .

Maunsell, K., Whetnall, E., and Rimington, C. (1947). Brit. J. exp. Path., 28, 331 .

Partridge, S. M. (1948). Biochem. J., 42, 238.

(1949). Nature, Lond., 164, 443.

Prausnitz, C. (1936). Spec. Rep. Ser. med. Res. Coun., Lond. No. 212 .

Rimington, C. (1940). Biochem. J., 34, 931.

—, Stillwell, D. E., and Maunseli, K. (1947). Brit. .. exp. Path., 28, 309 .

Somogyi, M. (1945). J. biol. Chem. 160, 61

Stillwell, D. E., Rimington, C., and Maunsell, K. (1947). Brit. J. exp. Path., 28, 325. 